\title{
HISTÓRIA E FILOSOFIA DA CIÊNCIA EM EVENTO DE ENSINO DE CIÊNCIAS
}

\author{
Suellen Cristine Isidoro Ribeiro ${ }^{1}$ \\ Verônica Pimenta Velloso ${ }^{2}$ \\ Maria Cristina do Amaral Moreira ${ }^{3}$
}

\section{Resumo}

As relações entre ciência e sociedade são cada vez mais complexas como resultado de mudanças no cotidiano das pessoas. No ensino de ciências, essas mudanças suscitam uma formação docente para o pensamento crítico acerca do processo de desenvolvimento científico-tecnológico e seus produtos. O estudo visou à inserção da História e Filosofia da Ciência como metodologia de ensino como forma de aproximar o saber sobre ciências do ensino de ciências. Para alcançar esse objetivo pesquisamos os trabalhos acadêmicos apresentados por quinze anos em evento de relevância para a pesquisa em ensino de ciências. A finalidade foi a de identificar e problematizar os trabalhos, estratégias e propostas pedagógicas que incluíssem a História e Filosofia da Ciência no ensino. Trata-se de pesquisa qualitativa, para a demarcação de panorama das pesquisas. Os resultados demonstraram haver poucos trabalhos empíricos envolvendo a História e Filosofia da Ciência e que as principais estratégias identificadas foram: jogos, experimentos, filmes, sendo mais recorrentes as que usam textos e questionários. No que diz respeito às disciplinas, a Física comparece com mais contribuições, como apontado em estudos anteriores. No que concerne aos objetivos do uso dessa metodologia, foi identificado que a maioria dos trabalhos analisados procurou aborda-la para que a ciência fosse entendida como um processo, influenciada por fatores históricos, sociais, econômicos, e não como um produto acabado.

Palavras-chave: História e filosofia da ciência. Ensino de ciências. Propostas didáticas.

\section{HISTORY AND PHILOSOPHY OF SCIENCE FROM SCIENCE EDUCATION EVENT}

\begin{abstract}
The relations between science and society are complex as a result of changes, among them the technological, in people's everyday life. In science education, these changes give rise to a teacher training that stimulates critical thinking about the scientific-technological development process and its products. The study aimed to problematize the insertion of History and Philosophy of Science in basic education as a way of approaching knowledge about sciences and science education. For this we researched the papers presented for fifteen years in a relevance event to science education research. The goal was identify and problematize strategies and pedagogical proposals of the papers including History and Philosophy of Science as a methodology. It is a qualitative research, for a demarcation of a research landscape. The results showed few empirical studies involving the History and Philosophy of Science and that, in the classroom, the main strategies adopted were: games,
\end{abstract}


experiments, films, and the most recurrent ones using texts and questionnaires. Regarding the disciplines, Physics has the most contributions, as pointed out in previous studies. Regarding the objectives of the analyzed studies, most of them sought to treat science as a process influenced by historical, social and economic factors, rather than as a product.

Keywords: History and philosophy of science. Science education; Teaching proposals.

\section{HISTORIA Y FILOSOFÍA DE LA CIENCIA EN EVENTO DE ENSEÑANZA DE CIENCIAS}

\section{Resumen}

Las relaciones entre la ciencia y la sociedad son complejas como resultado de los cambios, entre ellos el tecnológico, en la vida cotidiana de las personas. En educación científica, estos cambios dan lugar a una formación docente que estimula el pensamiento crítico sobre el proceso de desarrollo científico-tecnológico y sus productos. El estudio tuvo como objetivo problematizar la inserción de la Historia y la Filosofía de la Ciencia en la educación básica como una forma de acercarse al conocimiento sobre las ciencias y la educación científica. Para esto, investigamos los trabajos presentados durante quince años en un evento relevante para la ensenanza de la ciencia. El objetivo fue identificar y problematizar las estrategias y las propuestas pedagógicas de los trabajos que incluía la Historia y la Filosofía de la Ciencia como metodología. Es una investigación cualitativa, para una demarcación de un paisaje de investigación. Los resultados mostraron pocos estudios empíricos sobre Historia y Filosofía de la Ciencia y que, en el aula, las principales estrategias adoptadas fueron: juegos, experimentos, películas y las más recurrentes utilizando textos y cuestionarios. En cuanto a las disciplinas, la física tiene la mayor contribución, como se señaló en estudios anteriores. Con respecto a los objetivos de los estudios analizados, la mayoría de ellos buscaba tratar la ciencia como un proceso influenciado por factores históricos, sociales y económicos, más que como un producto.

Palabras clave: Historia y filosofía de la ciencia. Enseñanza de las ciencias. Propuestas didácticas.

\section{INTRODUÇÃO}

O ensino de ciências tem cada vez mais sentido amplo e necessário no cotidiano dos indivíduos, influenciado por novas tecnologias e pela velocidade com que as mudanças acontecem. Saber sobre a ciência e a tecnologia tem sido essencial no mundo contemporâneo. (MOREIRA, 2006). Esse aspecto ocupa papel fundamental para a compreensão de conhecimentos, procedimentos e valores que contribuem para que os cidadãos tomem as decisões e percebam as muitas aplicações e, ao mesmo tempo, as limitações e consequências do desenvolvimento científico-tecnológico para a qualidade de suas vidas. (CHASSOT, 2003). 
Analisando as concepções de alunos do Ensino Médio sobre ciência e tecnologia, e destas com a divulgação científica, Cunha (2009) identificou que esses apresentam conhecimentos parciais e fragmentados, percebendo a ciência e a tecnologia separadamente. Para Cunha, esse fato se deve, sobretudo, à fonte de informações utilizada, geralmente a mídia. Em relação à tecnologia demonstram uma valorização mais positiva do que à ciência, não se transformando em interesse por conhecer melhor seu funcionamento.

Em estudo realizado com docentes da educação básica foram identificadas três concepções de ciência incompatíveis com as pesquisas atuais sobre a construção do conhecimento científico. A compreensão "da superioridade do modelo de decisões tecnocráticas", as quais percebem o trabalho científico neutro em relação aos posicionamentos sociais, o que legitima as decisões dos cientistas como se não fossem influenciadas por fatores sociais, levando ao entendimento da ciência como verdade absoluta. Outra visão é a da "perspectiva salvacionista da ciência e tecnologia", na qual a ciência é vista como o caminho para resolver os problemas da humanidade, conduzindo ao bem-estar social. Somado a essas concepções, há ainda o mito do "determinismo tecnológico", que percebe a ciência como o caminho para o progresso, onde o futuro será melhor que o presente e que toda inovação tecnológica é boa em si mesma. (AULER; DELIZOICOV, 2001, p. 123).

Nesse sentido, a inserção da História e Filosofia da Ciência (HFC) na educação científica pode ser uma grande aliada, pois busca mostrar que o conhecimento científico é construído por meio de um processo histórico, em que o cientista, não vive isolado e, portanto, influenciado pelo seu meio social, político e econômico. As disciplinas científicas escolares embasadas na HFC têm mais condições de contribuir para o conhecimento amplo da ciência pelos alunos e para o aprimoramento dos professores, sobretudo pela epistemologia da ciência, tornando-as mais próximas da realidade. (MATTHEWS, 1995).

A despeito do vasto referencial que aponta os usos da HFC para o ensino de ciências, são poucos os trabalhos que fornecem corroboração empírica para esse argumento. (TEIXEIRA, GREGA; FREIRE JUNIOR, 2012). As intervenções metodológicas práticas, que integram o ensino de ciências com a HFC, não são fáceis de serem aplicadas, e pode-se observar um distanciamento entre a importância que lhes é atribuída e a sua aplicação de qualidade no chão da escola. Há consenso na literatura sobre a importância da HFC no ensino de ciências, mas a questão principal a ser aprofundada é como fazer efetivamente essa integração. (MARTINS, 2007).

Assim, esse estudo se propôs a uma análise sistematizada de trabalhos apresentados nos anais do Encontro Nacional de Pesquisa em Educação em Ciências (ENPEC) que compreendessem estratégias/propostas pedagógicas mencionadas por professores e/ou 
pesquisadores ao abordar a HFC no ensino básico, especificamente a partir de intervenções realizadas em salas de aula.

\section{A HISTÓRIA E FILOSOFIA DA CIÊNCIA E O ENSINO}

A sigla HFC faz referência a um conjunto de disciplinas autônomas entre si, a História da Ciência e a Filosofia da Ciência, que possuem surgimentos e desenvolvimentos próprios, mas que dispõem de uma relação íntima de mútuo benefício. (BASTOS FILHO, 2012). A HFC se preocupa em refletir e interpretar os aspectos sociais, históricos e filosóficos no processo de construção da ciência e do conhecimento científico.

Nesse sentido, a inclusão da HFC no ensino de ciências pode tornar as aulas mais desafiadoras e reflexivas, focando no desenvolvimento do pensamento crítico; promovendo uma melhor compreensão dos conceitos científicos; auxiliando no entendimento de aspectos da Natureza da Ciência $(\mathrm{NdC})$ e visando uma ciência mutável e não uma verdade inabalável. (MATTHEWS, 1995). Segundo Martins (2006) a HFC tem como possibilidades para o ensino de ciências: auxiliar na compreensão das inter-relações entre ciência, tecnologia e sociedade; perceber de forma mais concreta a real natureza da ciência, seus procedimentos e suas limitações; compreender que a ciência não é o resultado da aplicação de um método científico; auxiliar no aprendizado do próprio conteúdo científico e na transformação conceitual em relação ao conhecimento prévio de discentes e de docentes.

Além disso, a HFC pode funcionar como elemento motivador no processo de aprendizagem, pois contextualiza o conceito científico e pode auxiliar na necessária aproximação entre o aluno e o conhecimento científico. (CACHAPUZ, 2011). A HFC, como incentivo e motivação para as disciplinas científicas, está ligada à adoção de variadas estratégias didáticas, tais como textos, vídeos e experimentação, e não apenas à abordagem do conteúdo. Nesse aspecto, a dificuldade de análise da motivação se encontra em diferenciar o papel que cada uma das estratégias exerce na aprendizagem do aluno. Importante é que a HFC não deve ser inserida no ensino como um item ou disciplina diferenciada, ou mesmo como algo a mais em relação ao conteúdo científico, e sim como parte integrante da formação científica numa abordagem contextualista, ou seja, ensinada em seus diversos contextos: ético, social, histórico, filosófico e tecnológico. (MATTHEWS, 1995).

Com base na literatura, entendemos que em relação à HFC e o ensino de ciências, há dois grupos de objetivos que funcionam de modo integrado. O primeiro grupo dá ênfase na compreensão que o aluno tem dos produtos da ciência - leis e resoluções de equações -, estando associada com uma abordagem internalista, voltada ao conteúdo conceitual da ciência. Esse grupo pode levar a alguns riscos, tal qual o aluno reproduzir uma concepção de ciência neutra e linear, seguindo um caminho contínuo e progressivo. Outro risco é o do 
Artigo

doi: $10.20396 /$ rho.v18i4.8652249

anacronismo, julgar com ideias do presente o que aconteceu no passado, ou seja, reconstruir a história da ciência por um conhecimento atual, aceito pela comunidade científica no presente. Um terceiro risco que podemos apontar é o de que a HFC seja apenas tratada como pano de fundo, um elemento alegórico/ ilustrativo, o que traria pouca contribuição para o ensino sobre ciências. (MATTHEWS, 1995; MARTINS, 2001). O segundo grupo de objetivos trabalha a partir da construção do conhecimento científico, remetendo à compreensão da $\mathrm{NdC}$ e à relação histórica entre ciência e sociedade, segundo o entendimento de que o conhecimento científico deve envolver não somente seus produtos - leis e teorias - mas também o conhecimento dos procedimentos da ciência. (VANNUCCHI, 1997). Esse grupo de objetivos está associado à abordagem externalista, que tem como base os fatores extracientíficos presentes no desenvolvimento do conhecimento científico. O ideal seria que ambos os grupos fossem contemplados, pois uma análise completa implica recorrer tanto às considerações científicas, como também aos fatores extracientíficos. (OLIVEIRA; SILVA, 2011).

O importante é que o professor, ao optar pela utilização da HFC, esteja em consonância com a concepção de ciência e de ensino de ciências, tendo clareza de quais são os seus objetivos e limites, tendo em vista a grande gama de possibilidades de aproveitamento da HFC.

\section{METODOLOGIA DO ESTUDO}

Nesse artigo, para entender as propostas didáticas com HFC aplicadas em sala de aula da educação básica, investigamos ${ }^{4}$ trabalhos apresentados no Encontro Nacional de Pesquisa em Educação em Ciências (ENPEC), no período de 15 anos. O evento foi selecionado por ser um espaço privilegiado de intercâmbio de informações e experiências entre professores/pesquisadores em ensino de ciências. Trata-se do evento nacional de maior prestígio na área de ensino de ciências e que agrega diversas áreas temáticas de pesquisa inclusive a da HFC. Ademais, possui suas atas disponibilizadas na internet, o que facilita o acesso aos trabalhos. O período analisado (2000-2015) se inicia com a criação da área de avaliação em ensino ${ }^{5}$ da Coordenação de Aperfeiçoamento de Pessoal de Nível Superior (CAPES), o que nos possibilita delinear um panorama atualizado da relação entre HFC e o ensino de ciências.

A metodologia de pesquisa utilizada é de caráter bibliográfico e tem como objetivo mapear e discutir a produção acadêmica de uma área, buscando determinar que aspectos e dimensões vêm sendo destacados e privilegiados em diferentes épocas e lugares, nas diferentes formas e condições produzidas. (FERREIRA, 2002). Esse tipo de pesquisa de mapeamento pode facilitar a divulgação das informações produzidas no meio acadêmico, em especial na área de ensino, auxiliando possíveis transformações e melhorias no sistema escolar. Um dos desafios em se trabalhar com essa metodologia é conseguir explorar o 
grande volume de dados gerados, por isso torna-se tão importante a delimitação do objeto de investigação, que precisa estar balizado por critérios relevantes e explícitos ao longo da pesquisa. (ROSSETO et al., 2013).

A busca dos dados foi realizada na internet, acessando as atas de cada ano do evento selecionado no recorte temporal do estudo. Utilizaram-se os descritores "história"; "filosofia"; "sala de aula"; "didática", nos títulos e palavras-chave dos trabalhos apresentados. A escolha de tais descritores foi guiada em primeiro lugar pelos descritores mais amplos 'História' e 'Filosofia', principais referenciais teóricos da pesquisa e, posteriormente, pelos descritores 'sala de aula' e 'didáticos', relacionados à motivação da pesquisa. Os critérios para incluir os trabalhos no corpus da pesquisa foram os seguintes: o primeiro deles foi a presença de propostas didáticas com alunos em sala de aula, visto que existe uma ampla bibliografia recomendando a utilização da HFC no ensino de ciências. O segundo critério foi de que os trabalhos fossem realizados com alunos da educação básica, mais especificamente, Ensino Fundamental II, segundo segmento ( $6^{\circ}$ ao $9^{\circ}$ anos) e Ensino Médio. Essa delimitação, além de incluir o $9^{\circ}$ ano, no qual conceitos de física e química são explorados no currículo escolar, deveu-se ao interesse da autora principal da pesquisa, que atua como docente nesses níveis escolares.

Foram selecionados e lidos integralmente trinta e um trabalhos. No que diz respeito à codificação dos trabalhos, essa foi feita de forma que cada um deles possuísse um código individual ao longo da pesquisa. Esse código indicou o congresso - por meio da letra 'E' -e a sequência numérica em relação aos trabalhos selecionados. Para cada ano de evento analisado elaboramos duas planilhas, uma primeira nomeada "Identificação", na qual colocamos as informações consideradas principais do trabalho. E uma segunda planilha, nomeada de "Análise", que foi preenchida após a leitura mais minuciosa dos textos, trazendo informações sobre o processo da pesquisa narrada no trabalho. Essa planilha é composta pelos itens: trabalho (identificação individual); nível de escolaridade (ano letivo referente à pesquisa); disciplina (matéria escolar); materiais/métodos (etapas da atividade); objetivos; resultados e limites (apontados pelo autor). Após organização e elaboração desses dois grupos de planilhas de cada ano do ENPEC, foram elaboradas duas planilhas de síntese das informações coletadas. A Tabela 1 apresenta o modelo da planilha "Identificação" com os trabalhos citados nesse artigo.

Tabela 1 - Planilha Identificação ENPEC

\begin{tabular}{ccccc} 
Trabalho & Ano & Autor (es) & Título & (continua) \\
E1 & 2001 & $\begin{array}{c}\text { Ellen Suzi C. L. } \\
\text { Constantino/ Micheline C. } \\
\text { L. Dias/ Marcelo B. C. Leão }\end{array}$ & $\begin{array}{c}\text { A construção histórica da } \\
\text { tabela periódica como } \\
\text { proposta de aprendizagem }\end{array}$ & PE \\
\hline
\end{tabular}


Tabela 2 - Planilha Identificação ENPEC

(continuação)

\begin{tabular}{|c|c|c|c|c|}
\hline E2 & 2005 & $\begin{array}{l}\text { Elizabeth Mattiazzo-Cardia/ } \\
\text { Renata Ueno/ Mara Sueli } \\
\text { Simão Moraes }\end{array}$ & $\begin{array}{c}\text { A dívida pública como tema } \\
\text { transversal/ político social } \\
\text { em aulas de matemática no } \\
\text { ensino fundamental }\end{array}$ & $\mathrm{SP}$ \\
\hline E4 & 2005 & $\begin{array}{l}\text { Estevam Rouxinol dos } \\
\text { Santos Neto/ Maurício } \\
\text { Pietrocola P. de Oliveira }\end{array}$ & $\begin{array}{l}\text { Identificando o obstáculo } \\
\text { cultural em aulas de física } \\
\text { do ensino médio }\end{array}$ & SP \\
\hline E5 & 2005 & $\begin{array}{l}\text { Hélio Oliveira Rodrigues / } \\
\text { José Roberto da Silva }\end{array}$ & $\begin{array}{l}\text { Papiro de Moscou e } \\
\text { RHIND: Resolução de } \\
\text { Equação do } 2^{\circ} \text { Grau }\end{array}$ & ---- \\
\hline E7 & 2011 & $\begin{array}{c}\text { Adolfo Guilherme Krüger/ } \\
\text { Mariana Lopes Teixeira/ } \\
\text { Joanez Aires }\end{array}$ & $\begin{array}{l}\text { A Tabela Periódica a partir } \\
\text { da abordagem História e } \\
\text { Filosofia da Ciência: análise } \\
\text { de uma proposta didática }\end{array}$ & PR \\
\hline E11 & 2011 & $\begin{array}{c}\text { Patrícia Silva Costa/ } \\
\text { Alessandra Alves da } \\
\text { Cunha/Joanez Aparecida } \\
\text { Aires }\end{array}$ & $\begin{array}{l}\text { Análise de uma Proposta } \\
\text { Didática sobre } \\
\text { radioatividade a partir da } \\
\text { História e Filosofia da } \\
\text { Ciência }\end{array}$ & PR \\
\hline E12 & 2011 & $\begin{array}{c}\text { Tatiana Tavares da Silva/ } \\
\text { Maria Elice Brzezinski } \\
\text { Prestes }\end{array}$ & $\begin{array}{c}\text { História da Biologia no } \\
\text { ensino: análise das } \\
\text { concepções de alunos sobre } \\
\text { os métodos científicos, } \\
\text { através de episódios } \\
\text { históricos de Charles } \\
\text { Darwin }\end{array}$ & SP \\
\hline E13 & 2011 & $\begin{array}{c}\text { Eliane Gonçalves dos } \\
\text { Santos/ Neusa Maria John } \\
\text { Scheid }\end{array}$ & $\begin{array}{l}\text { História da ciência na } \\
\text { educação básica: } \\
\text { contribuições do cinema }\end{array}$ & $\underset{\mathrm{i}}{\text { Urugua }}$ \\
\hline E14 & 2011 & $\begin{array}{l}\text { Stephanie Angela Todesco/ } \\
\text { Tatiane Soares Rodrigues/ } \\
\text { Joanez Aparecida Aires }\end{array}$ & $\begin{array}{l}\text { História e Filosofia da } \\
\text { Ciência: uma proposta para } \\
\text { o ensino de ácidos e bases }\end{array}$ & PR \\
\hline E15 & 2011 & $\begin{array}{c}\text { Rita de Cássia Balieiro } \\
\text { Rodrigues/ Wagner Wilson } \\
\text { Furtado }\end{array}$ & $\begin{array}{c}\text { Jogos teatrais de História da } \\
\text { Ciência }\end{array}$ & GO \\
\hline
\end{tabular}


Tabela 3 - Planilha Identificação ENPEC

\begin{tabular}{|c|c|c|c|c|}
\hline E19 & 2013 & $\begin{array}{l}\text { Rita de Cássia Balieiro } \\
\text { Rodrigues/Wagner } \\
\text { Wilson Furtado }\end{array}$ & $\begin{array}{l}\text { Jogos teatrais no estudo da } \\
\text { construção histórica do } \\
\text { conhecimento sobre modelos } \\
\text { atômicos no ensino fundamental }\end{array}$ & $\frac{\text { clusã }}{\mathrm{GO}}$ \\
\hline E24 & 2015 & $\begin{array}{c}\text { Luciana Valéria } \\
\text { Nogueira/ Kelma Cristina } \\
\text { de Freitas }\end{array}$ & $\begin{array}{l}\text { Análise de aspectos da Natureza } \\
\text { da Ciência (NdC) e } \\
\text { motivacionais em estudantes do } \\
\text { Ensino Médio mediada por } \\
\text { sequência didática centrada na } \\
\text { replicação de experimentos } \\
\text { históricos darwinianos }\end{array}$ & SP \\
\hline E25 & 2015 & $\begin{array}{c}\text { Anna Cássia de Holanda } \\
\text { Sarmento/ Cássia Regina } \\
\text { Reis Muniz /Natália } \\
\text { Rodrigues da Silva / } \\
\text { Thiago Serravalle de Sá / } \\
\text { Valter Alves Pereira / } \\
\text { Claudia de Alencar Serra } \\
\text { e Sepúlveda }\end{array}$ & $\begin{array}{l}\text { Como ensinar citologia para } \\
\text { estudantes do ensino médio e } \\
\text { promover uma visão informada } \\
\text { sobre características da ciência }\end{array}$ & BA \\
\hline
\end{tabular}

Fonte: autores

Os dados obtidos nessas planilhas foram organizados para análise com base em três aspectos: o cenário geral das pesquisas, o aspecto escolar e o aspecto epistêmico.

O cenário geral dos trabalhos buscou traçar um panorama das pesquisas empíricas de HFC no ensino básico brasileiro de ciências nos últimos 15 anos, relativo a questões quantitativas, de divisão geográfica e de instituições envolvidas. $\mathrm{O}$ aspecto escolar relaciona os itens das pesquisas que estão dentro do contexto escolar, como a disciplina trabalhada, conteúdo específico e níveis de escolaridade. $\mathrm{O}$ aspecto epistêmico, o mais complexo da análise, se preocupa em relacionar as questões de conteúdo, procurando dados como objetivos de pesquisa, resultados alcançados, materiais e métodos utilizados e limites apontados.

Buscando identificar como esses dados se integram no que indicam as pesquisas teóricas para ensino de ciências na relação com a HFC, esclarecemos que só foram considerados os objetivos, resultados e limites apontados explicitamente por cada trabalho, não tendo sido analisado o referencial teórico, pois entendemos que os objetivos da pesquisa trazem (ou deveriam trazer) elementos do referencial teórico utilizado e, além disso, sintetizam os aspectos considerados mais relevantes para o autor. 


\section{RESULTADOS E DISCUSSÕES}

Quanto ao cenário geral das pesquisas, embora a distribuição de trabalhos tenha oscilado nesses quinze anos, como mostra o Gráfico 1, identificamos a predominância dos trabalhos principalmente a partir da edição do ano de 2011. As últimas edições do ENPEC (2011, 2013 e 2015) somam vinte cinco dos trinta e um estudos selecionados, enquanto as outras cinco edições $(2001,2003,2005,2007$ e 2009) somam apenas seis, sendo que nas edições de 2003 e 2009 , nenhum trabalho foi selecionado.

Gráfico 1 - Trabalhos do ENPEC/ ano

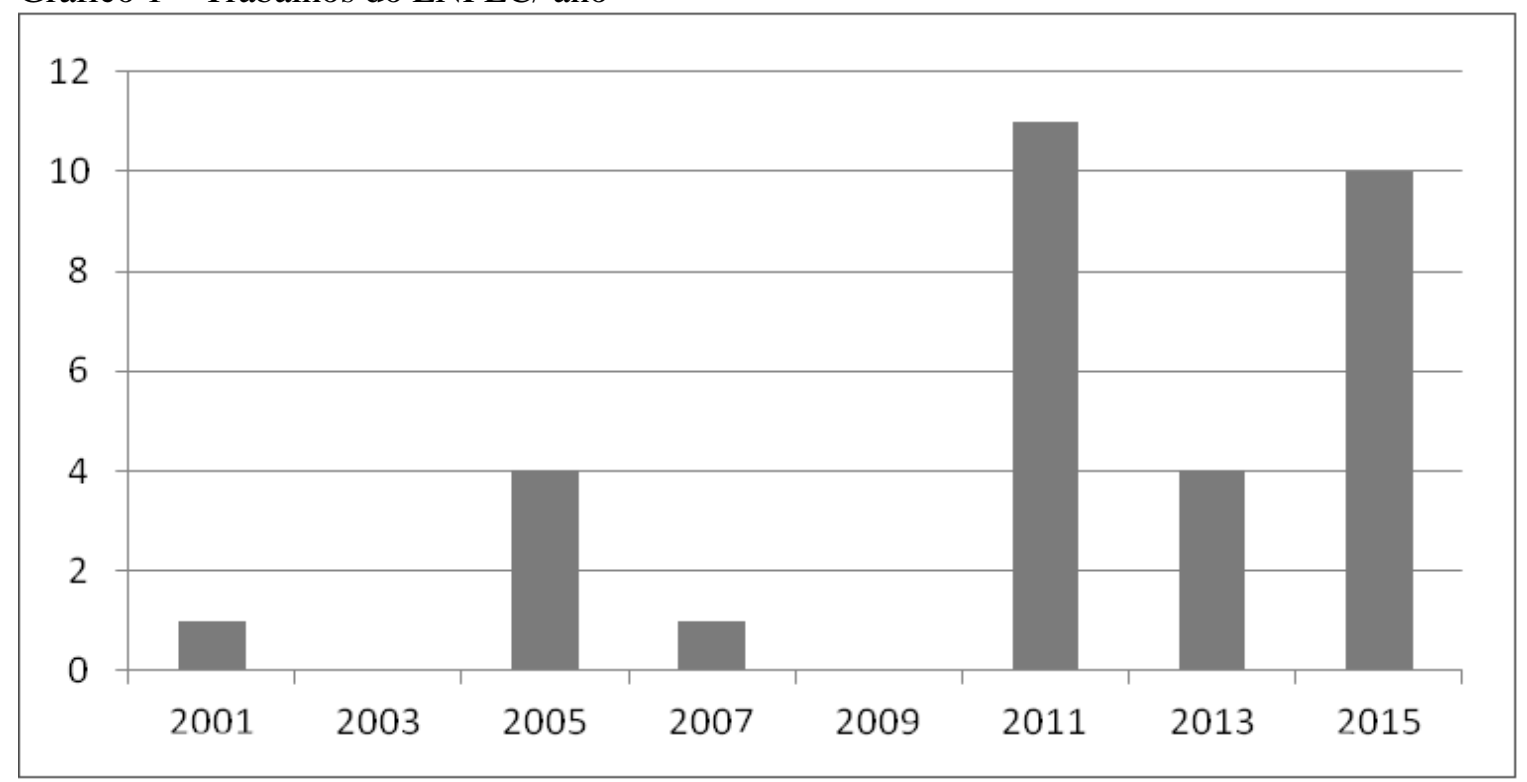

Fonte: Autores

Esse resultado aponta para um crescimento do interesse para com essa vertente nos últimos cinco anos, embora essa perspectiva já esteja presente no ensino, e alguns pesquisadores entendam que no Brasil já eram encontradas publicações desde 1985, mas que estas se expandiram a partir dos anos 2000.

A divisão dos trabalhos pelas regiões do Brasil também apresenta certa discrepância de distribuição, a maioria (22) foram desenvolvidos na região Sudeste, dentre os restantes, nove estão na região Sul, quatro no Nordeste e quatro no Centro-Oeste, sendo que dois trabalhos dessa região (E15 e E19) correspondem à mesma pesquisa apresentada em momentos diferentes. Chamou-nos a atenção à ausência de trabalhos realizados na região Norte e a presença de um trabalho desenvolvido no Uruguai. 


\section{Revista HIIS'TNDBR On-lime}

Gráfico 2 - Divisão dos trabalhos por Região

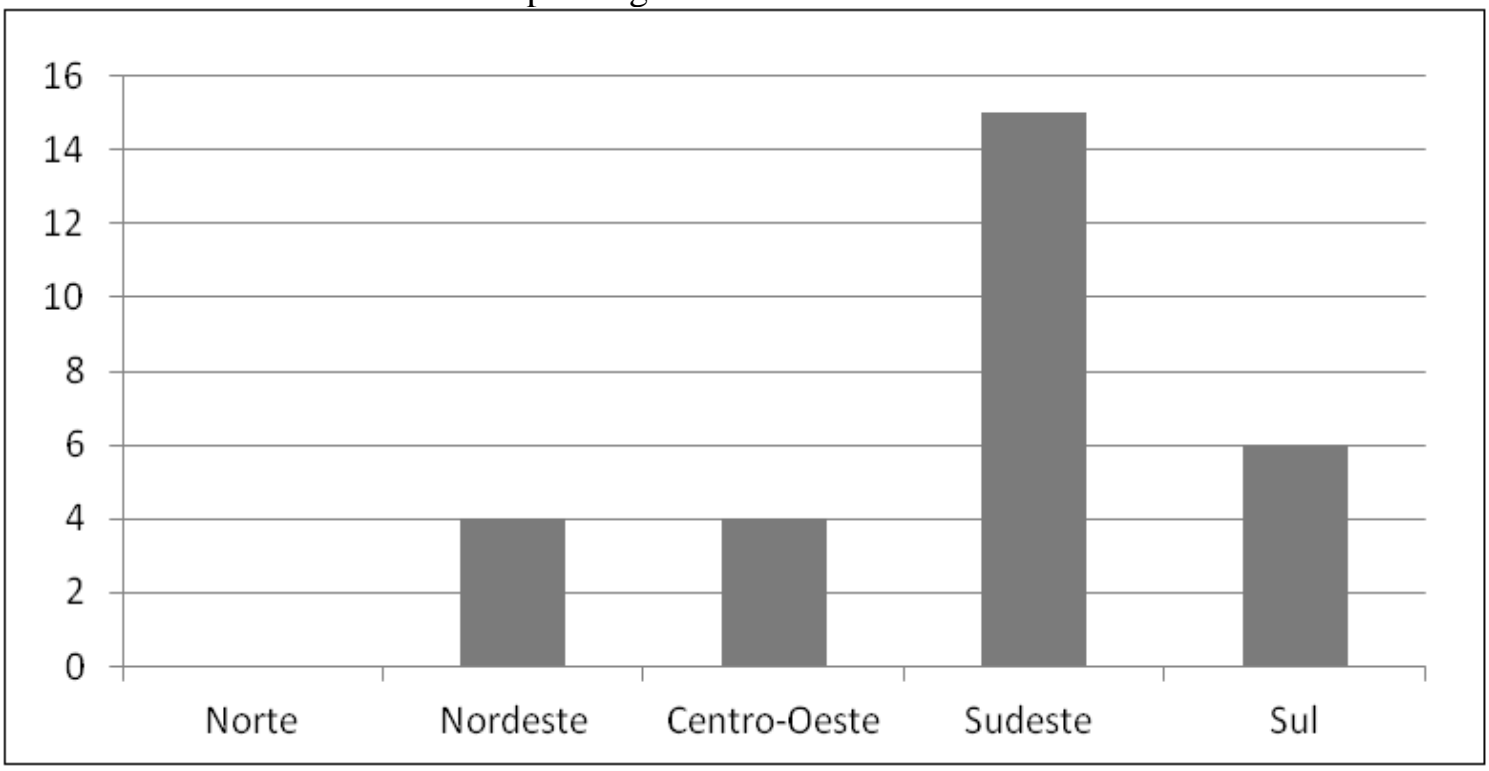

Fonte: Autores

Em relação às instituições nas quais foram desenvolvidos esses trabalhos, identificamos quinze delas, e a relação da quantidade de trabalhos por instituição citada variou de um a quatro. Em consonância com os dados anteriores, podemos perceber a concentração de trabalhos na região sudeste, em especial no eixo Rio-São Paulo.

Gráfico 3 - Divisão dos trabalhos por instituição

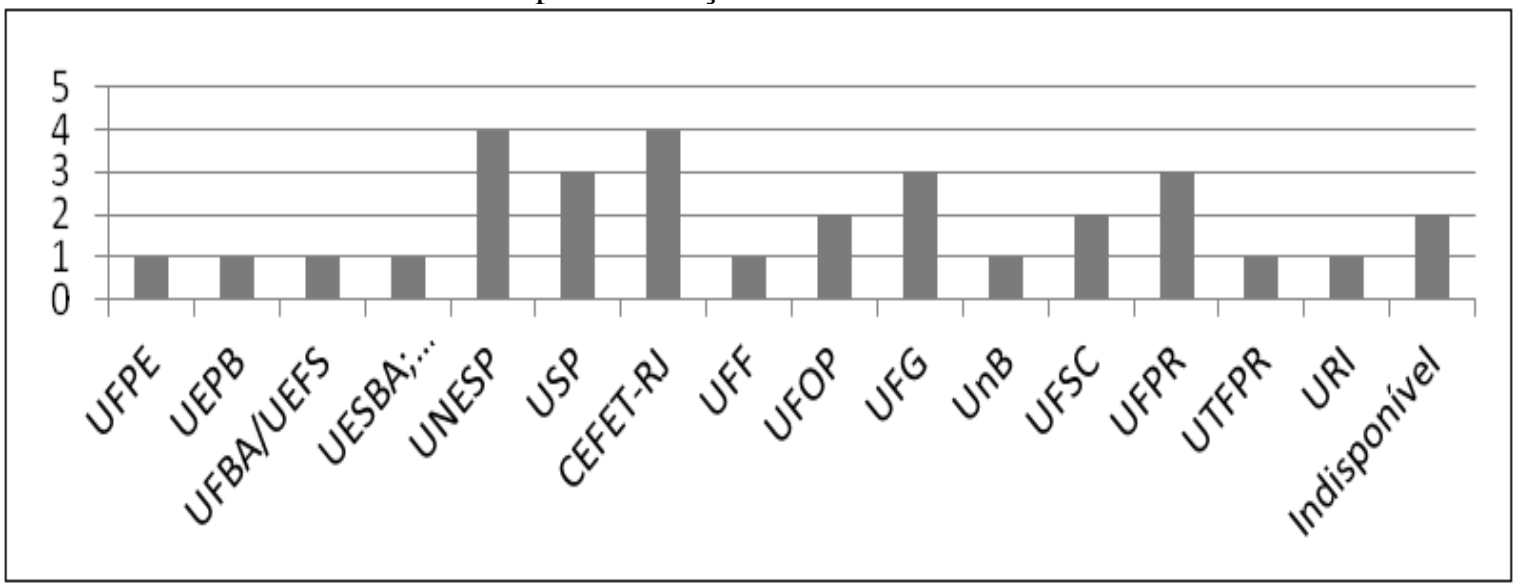

Fonte: Autores

Delizoicov, Slongo e Lorenzetti (2007), em pesquisa exploratória sobre as cinco primeiras edições do ENPEC (1997-2005), encontraram como resultado que a maioria dos autores dos trabalhos apresentados tinha como procedência as Instituições de Ensino Superior (IES). Podemos perceber certos paralelos com os resultados aqui identificados. Por exemplo, nossos resultados apontam que as instituições que mais desenvolveram pesquisas empíricas, sobre a relação entre HFC e o ensino de ciências foram: UNESP, 
Artigo

doi: $10.20396 /$ rho.v18i4.8652249

CEFET-RJ (quatro trabalhos cada) e USP, UFG, UFPR (três trabalhos cada). Esses autores consideram que os IES com mais participação nesses cinco ENPEC foram a UNESP e a USP, identificadas com destaque neste estudo. Os autores citam ainda a UFSC e a UFF, instituições de procedência dos pesquisadores que aparecem também nos nossos dados. Tratam os CEFET como instituições de características diferentes dos IES e, por essa razão, resolvemos não comparar esse aspecto com os dados obtidos em nossa pesquisa, visto que os autores não distinguiram os CEFET dos diferentes estados.

Podemos perceber anuência entre os resultados obtidos pela pesquisa de Delizoicov Slongo e Lorenzetti e a que realizamos, sobretudo nas principais instituições que pensam o ensino de ciências na interseção com as pesquisas para promover a HFC em sala de aula. Ou seja, as instituições que estudam e produzem sobre o ensino de ciências demonstram certa continuidade de interesse nessa perspectiva de estudos.

Quanto aos aspectos escolares, dos trinta e um trabalhos analisados sobressaíram os voltados para o ensino médio, com dezessete ocorrências, e doze deles voltados para o ensino fundamental II. Esse resultado pode ter relação com o fato de as disciplinas Física, Química e Biologia serem ensinadas separadamente e ganharem mais espaço no currículo a partir do ensino médio. Fica explícito que a disciplina Física tem sido aquela que mais tem se dedicado a desenvolver trabalhos a partir da vertente HFC. A Física foi encontrada em quatorze dos trinta e um trabalhos. Essa predominância foi constatada também na pesquisa de Delizoicov, Slongo e Lorenzetti. Esse fato pode ter relação com o histórico da área de ensino de ciências que teve, no seu surgimento, pesquisas voltadas ao ensino de Física. O Gráfico 4 a seguir mostra a divisão dos trabalhos por disciplina científica.

Gráfico 4 - Divisão por disciplina científica

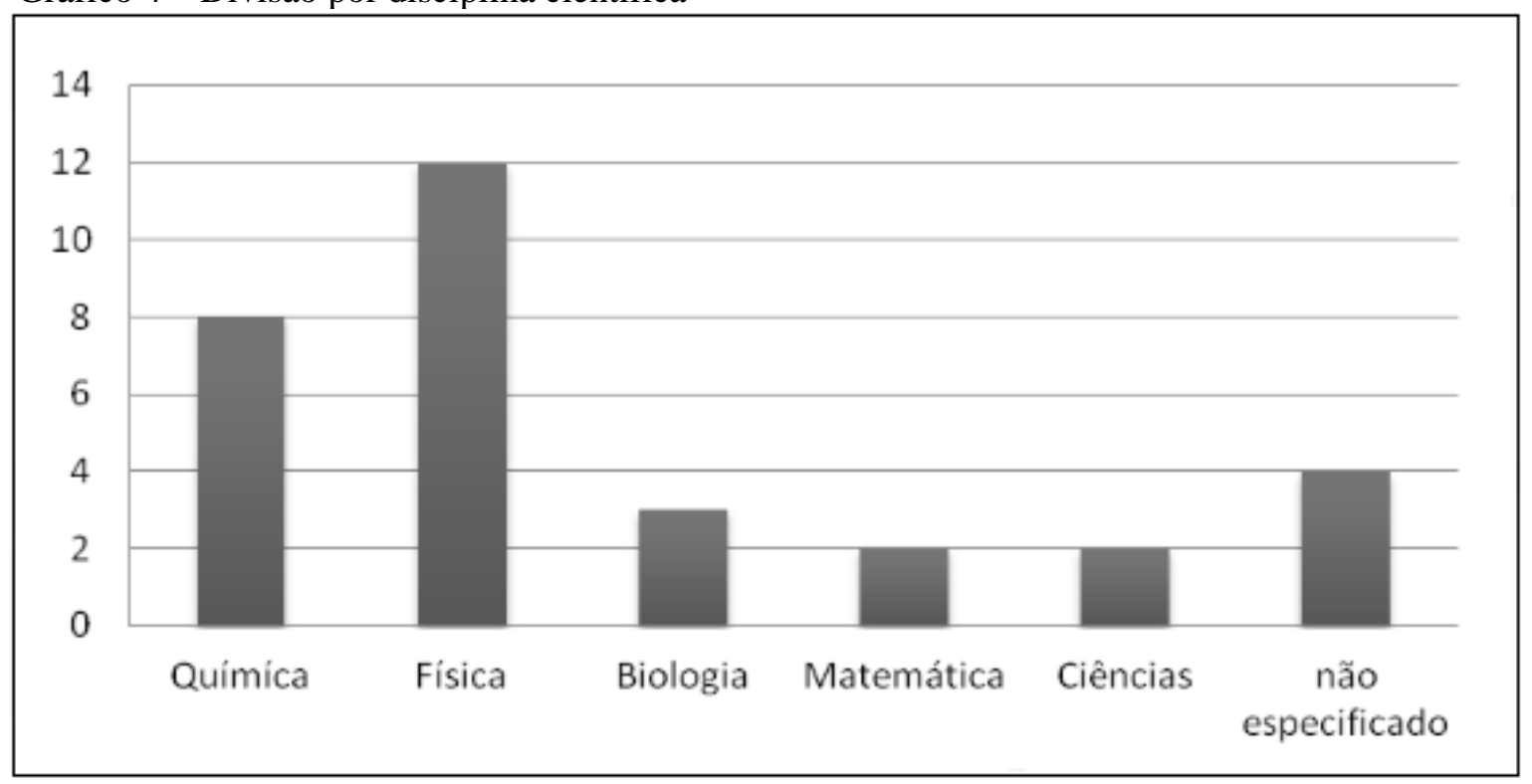

Fonte: Autores 
Como podemos notar pelo Gráfico 4, quatro trabalhos não mencionaram em qual disciplina a atividade proposta foi realizada. Outro resultado relevante é que apesar de todos os trabalhos utilizarem a HFC como forma de contextualizar os conteúdos disciplinares ou questões da $\mathrm{NdC}$, apenas dois se declaram interdisciplinares: o E13 e o E24. No trabalho E24 é possível perceber uma preocupação com essa questão, uma vez que, na proposta didática, os autores relatam uma cooperação entre as disciplinas Redação e Biologia, na solicitação da elaboração de um artigo científico com base nos conteúdos científicos e da NdC, tal como no trecho transcrito: "Privilegiando a interdisciplinaridade, fizemos uma parceria com a professora de Redação. Esta orientou os alunos quanto ao gênero específico. $\mathrm{O}$ artigo final serviu como avaliação também para essa disciplina." (NOGUEIRA, FREITAS, 2015, p. 4).

No que se refere aos aspectos epistêmicos, buscamos analisar quais as principais motivações para utilizar a HFC em sala de aula. Os objetivos de pesquisa encontrados foram categorizados em três grupos: 'conhecimento', 'processo' e 'conhecimento + processo'. Entendemos que a utilização da HFC já indica uma percepção da necessidade e uma vontade, por parte do professor/ pesquisador, de discutir o processo de construção do conhecimento científico e a inserção histórico-social do conhecimento, como indicado pela literatura da área. A divisão que propomos para os objetivos apontados nos trabalhos está relacionada à forma como a HFC contribuiu para a pesquisa. Se ela é vista unicamente como pano de fundo para discutir questões do conteúdo científico, classificamos o trabalho na categoria 'conhecimento'. O trabalho E1 serve de exemplo dessa categoria, pois indica que:

\footnotetext{
O objetivo desse trabalho é propor a utilização da história da química como um instrumento para que o professor possa fazer a mediação no ensino da tabela periódica. Acreditamos que essa metodologia poderá permitir uma melhor compreensão por parte do aluno, uma vez que a memorização, incentivada por alguns professores, não possibilita aos aprendizes a compreensão das propriedades químicas e físicas dos elementos. (CONSTANTINO, DIAS, LEÃO, 2001, p. s/n).
}

Podemos perceber no trecho acima que a HFC teve como função facilitar a compreensão do conhecimento científico, nesse caso, a tabela periódica.

$\mathrm{Na}$ categoria 'processo' colocamos os trabalhos que indicavam como principal objetivo trabalhar com o aluno as relações existentes no processo de construção do conhecimento científico. Nesse sentido, seria mais importante aprender sobre ciência do que sobre seus produtos. $\mathrm{O}$ trabalho (E4) serve de exemplo dessa categoria, pois o objetivo do trabalho foi analisar nas concepções dos alunos os indícios do que eles chamaram de 'obstáculo cultural', como no trecho: "A ideia de que toda física, enquanto importante área de pesquisa, só é possível de ser produzida e elaborada em países ricos e desenvolvidos, cabendo aos países periféricos como o Brasil importá-la e consumi-la." (SANTOS NETO, OLIVEIRA, 2005, p. 1). Os autores deste trabalho mencionam que desenvolveram a ideia 
de 'obstáculo cultural' a partir do conceito de 'obstáculo epistemológico' de autoria de Bachelard (1996), por terem percebido o limitado entendimento entre os alunos sobre a produção da ciência e propuseram maneiras de desconstruí-lo. Nesse trabalho, o objetivo está focado na discussão sobre o funcionamento da ciência e seus aspectos sóciohistóricos. Quer dizer, a ênfase não foi a de discutir um conceito específico da física, mas as possibilidades de desenvolvimento da ciência em relação ao contexto social e econômico.

Abrigamos ainda nessa categoria trabalhos que buscavam identificar as concepções dos alunos sobre ciência e cientistas, como é o caso do trabalho E12, cujo objetivo era: "Conhecer e analisar as concepções de alunos sobre alguns aspectos dos métodos das ciências, particularmente no que diz respeito às etapas da investigação experimental." (SILVA, PRESTES, 2011, p. 3).

A terceira categoria 'conhecimento + processo' diz respeito aos trabalhos que tentaram unir as duas categorias acima apontadas. O objetivo desses trabalhos é ao mesmo tempo proporcionar ao aluno um conhecimento dos produtos da ciência, e o seu processo de construção. O trabalho E11 analisou uma unidade didática que objetivava tratar dos conteúdos químicos específicos (referentes à radioatividade) e fazer os alunos refletirem sobre a construção do conhecimento científico. O Gráfico 5 mostra que os objetivos mais referidos são os que apontam o processo de construção do conhecimento científico.

Gráfico 5 - Divisão dos objetivos

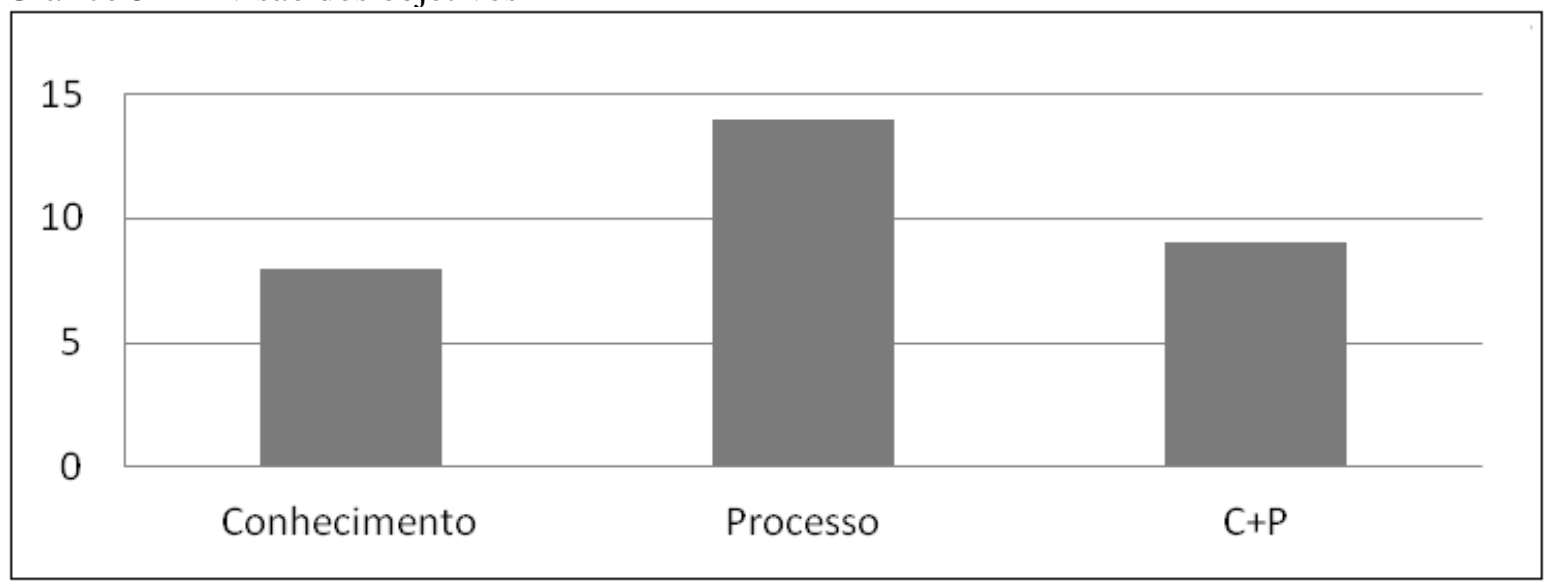

Fonte: Autores

Quanto aos seus objetivos, oito trabalhos focam no conteúdo científico. Por outro lado, quatorze, dos trinta e um, colocam o conhecimento científico em segundo plano. A equiparação entre esses dois objetivos foi identificada em nove trabalhos. Esse resultado tem muita relação com as possibilidades que a literatura aponta sobre a utilização da HFC no ensino, uma vez que propõe trabalhar a ciência para além dos seus produtos, a partir de uma visão mais ampla e que inclua seus processos. 
No que diz respeito às propostas sugeridas nos trabalhos para a educação básica, podemos perceber uma variedade delas; textos diversos da área sobre o fenômeno estudado, fontes primárias, ou seja, textos produzidos contemporaneamente. A reprodução de experimentos históricos, esquetes teatrais, debates, questionários, jogos didáticos e aulas expositivas também foram utilizados nos trabalhos analisados, assim como recursos tecnológicos, reprodução ou confecção de vídeos e slides.

Outro fator que nos chamou a atenção foi o fato de as estratégias - textos e questionários - terem sido utilizadas associadas com outras estratégias como, por exemplo, experimentação e recursos tecnológicos. Esse fato pode caracterizar os modelos de estratégias mais comuns na sala de aula em detrimento de outras menos usadas. O Gráfico 6 mostra quantas vezes uma estratégia ou material didático ocorreu nos trabalhos analisados.

Gráfico 6 - Estratégias e Materiais

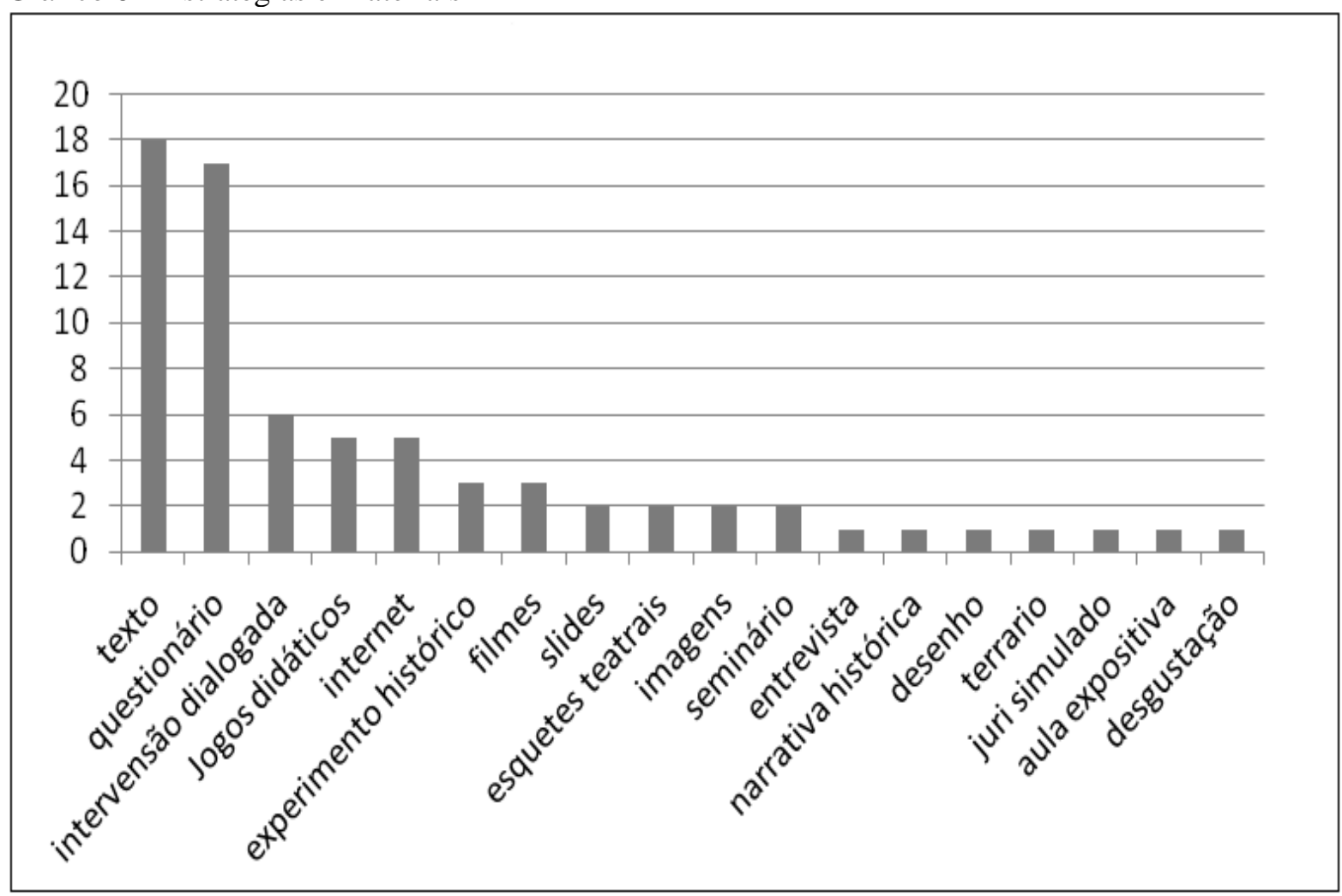

Fonte: Autores

Foram encontradas mais de uma estratégia e/ou material em um mesmo trabalho. Em dois trabalhos (E2; E5) não foi possível identificar quais foram as estratégias e/ou materiais utilizados. Esse estudo corrobora outros que identificaram o texto como estratégia didática privilegiada na implementação da HFC em sala de aula. (VITAL; GUERRA, 2015). O trabalho de Vital e Guerra (2015) identificou que os textos são 
materiais utilizados majoritariamente numa perspectiva de diálogo entre os sujeitos envolvidos no processo: o autor, professor e o aluno/leitor, além disso:

[...] na maioria das propostas, observamos a utilização de vários recursos didáticos articulados aos textos com a finalidade de dar dinamismo ao processo educativo e promover experiências que viabilizassem a compreensão das dimensões sociais, culturais e históricas do conhecimento científico. (VITAL, GUERRA, 2015, p. 7).

No que diz respeito aos questionários, citados em 17 trabalhos, esses são utilizados principalmente como instrumento de coleta de dados para as respectivas pesquisas. É o caso do trabalho E14, que analisa uma proposta didática para a utilização da abordagem HFC nas aulas de química com a finalidade de trabalhar o conteúdo de ácidos e bases (um questionário inicial e final).

Nossos resultados indicaram igualmente que a utilização de textos diversos em conjunto com outras estratégias comparece como principal fonte de aproximação entre a HFC e o ensino de ciências. Em relação aos resultados alcançados pelos trabalhos analisados, os autores apontaram inúmeros resultados como podem ser observados no Gráfico 7.

Gráfico 7 - Resultados

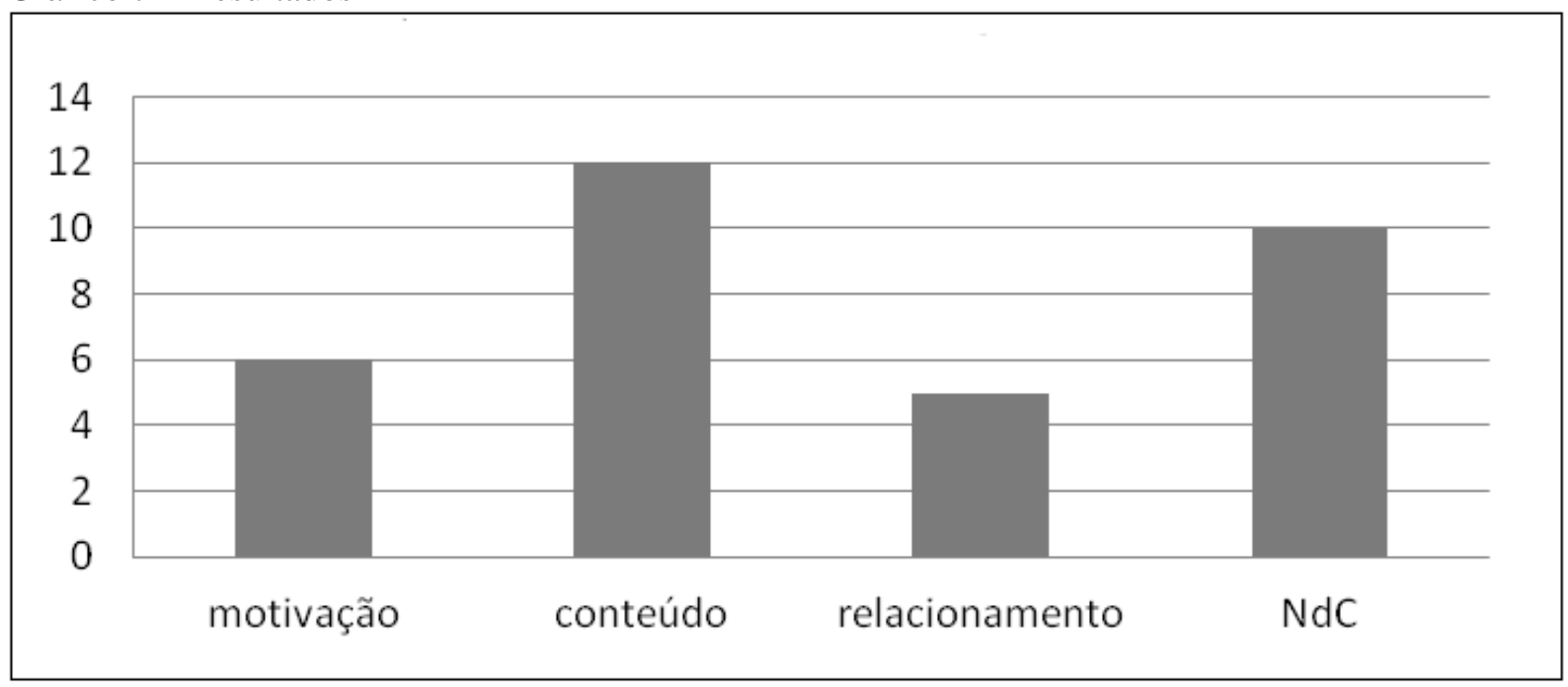

Fonte: Autores

Dentre os resultados, alguns trabalhos apontam que o uso da HFC proporcionou mais motivação para os estudos por parte dos alunos. A seguir, apresentamos um trabalho que menciona a motivação:

A inclusão dessa nova metodologia tornou mais ativo e relevante o ensino da tabela periódica, nos participantes dessa investigação, despertando o interesse dos alunos, propiciando situações de investigação e de construção de 
conhecimento que nem sempre são criadas em aulas teóricas-expositivas. (CONSTANTINO, DIAS, LEAO, 2001, p.s/n).

Outro aspecto importante dos resultados foi que doze trabalhos incluíram a aprendizagem do conteúdo como resultado alcançado. Esses trabalhos apontam que explorar a HFC no ensino de ciências pode contribuir com a aprendizagem dos conteúdos específicos, leis e teorias científicas, para além da simples memorização. Como aponta o trabalho E1:

Percebeu-se um aumento significativo das respostas certas e uma diminuição das incorretas. Vale a pena salientar que o percentual de alunos que não responderam diminuiu bastante, acreditando-se assim que, através das atividades aplicadas os alunos foram incentivados a responder às questões. (CONSTANTINO, DIAS, LEAO, 2001, p. s/n).

Outro resultado que esteve presente foi o de que a HFC contribui para o relacionamento entre os alunos de uma turma, tanto entre eles como com o professor. Como exemplo, temos o trabalho E1: "Outro ponto a ser destacado é a socialização escolar. A relação de diálogo, aluno-aluno e professor-aluno, foi favorecida, pois por meio dessas atividades didáticas ocorreu uma maior integração dos participantes ativos." (CONSTANTINO, DIAS, LEAO, 2001, p.s/n). Podemos perceber que mais de um resultado pode ter sido apontado pelo mesmo trabalho, como foi o caso de E1, que indicou melhora na aprendizagem dos conteúdos dos alunos e melhora na sociabilidade da classe, decorridos das atividades desenvolvidas com a HFC.

Entre os resultados apontados, não poderiam deixar de aparecer aqueles que enfatizaram a relação entre HFC e o aprendizado NdC como forma de aprender ciências. Como apontado no trabalho E25, a NdC é um dos maiores ganhos epistemológicos quando se ensina por intermédio da HFC.

[...] contribuiu para que os estudantes compreendessem o papel dos modelos na ciência, a provisoriedade e multiplicidade dos modelos, que a ciência é influenciada por fatores externos, além de possibilitar uma melhor compreensão das atividades científicas de idealização e abstração para a construção de modelos e interpretação da realidade, contribuído para uma compreensão mais profunda da relação entre teoria, modelo e realidade. (SARMENTO et al, 2015, p. 7).

Em relação aos limites das pesquisas, quando o objetivo é usar a HFC, podemos inferir que nem todos os trabalhos analisados identificaram problemas no que pretendiam com a proposta didática. Aproximadamente metade do corpus não menciona nenhum limite ou dificuldade em relação à atividade proposta. O trabalho E24 apontou duas categorias principais de limites, uma delas a própria $\mathrm{NdC}$, tal como no exemplo a seguir

[...] percebe-se que ainda há muitos desafios a serem vencidos. As dificuldades em apreender certos aspectos da $\mathrm{NdC}$, tais como a questão do método científico único, a ciência como portadora de verdades absolutas, os experimentos como 
prova da verdade científica e a não diferenciação entre hipótese, teoria e leis indicam caminhos a serem percorridos. (NOGUEIRA, FREITAS, 2015, p. 7).

Os trabalhos apontam para a dificuldade de desconstruir nos alunos a imagem ingênua de ciência que muitas vezes eles constroem fora da escola, como por exemplo, pela mídia. Mesmo após o trabalho desenvolvido em sala restam ainda interpretações inadequadas em relação ao desenvolvimento da ciência, como aponta o trabalho E12:

A maioria dos alunos conseguiu identificar as hipóteses pressupostas por Darwin, além de algumas questões sobre métodos científicos. Muitos alunos, contudo, acreditam que os experimentos são formas de comprovação de ideias, implicando desconhecimento sobre o papel do levantamento de dados como corroboração, e não comprovação, de teorias científicas. (SILVA, PRESTES, 2011, p. 4).

Esses resultados retratam a necessidade de se continuar com o trabalho de desconstrução e reconstrução da imagem da ciência com os alunos, pois como concluiu o trabalho E7 esses dados podem e devem alcançar outra função:

[...] de permitir um levantamento das concepções dos alunos, com o objetivo de diagnosticar onde estão ancoradas aquelas concepções e então, a partir dess4e diagnóstico, elaborar outras propostas didáticas, também tendo por base a abordagem em HFC, para que, aos poucos, se possa ir "desconstruindo" séculos de um ensino de ciências marcado pela memorização de uma ciência a-histórica, verdadeira, linear, cumulativa, de gênios e masculina. (KRÜGER, TEIXEIRA, AIRES, 2011, p. 11).

Outro motivo limitador do uso da HFC diz respeito ao próprio conteúdo, e apesar da maioria dos trabalhos mostrarem uma melhora conceitual dos alunos em relação aos conteúdos visados na aprendizagem, uma parte deles aponta que, em alguns casos, os conteúdos específicos não são compreendidos pelo aluno, entendendo que esse é um limite encontrado.

\section{CONSIDERAÇÕES FINAIS}

Nesta pesquisa buscamos entender como os pesquisadores/professores da educação básica têm se apropriado e praticado a articulação da HFC com o ensino de ciências por meio dos trabalhos apresentados no ENPEC num intervalo de quinze anos (2000-2015) de pesquisa na área de ensino.

Os resultados apontaram que, apesar de uma ampla literatura apontando a importância do uso da HFC articulada ao ensino de ciências, ainda são poucas as propostas de implementação desse tipo de trabalho divulgado no maior encontro de pesquisadores em ensino de ciências do país. Além disso, os trinta e um trabalhos que discutem essa vertente ainda têm um apelo maior para o Ensino Médio, sobretudo na disciplina de Física, o que nos faz pensar na necessidade de avolumar as pesquisas em outras áreas das ciências 
naturais e nos diferentes níveis de ensino. Um dado bastante positivo foi o da diversificação de instituições de ensino superior que têm se debruçado sobre a HFC na interseção com o ensino de ciências. Esse fato pode indicar que a área de pesquisa em ensino de ciências está ampliando o espaço de atuação, apesar de ainda ser notória a concentração das investigações em instituições da região Sudeste.

Em relação aos objetivos dos trabalhos, percebemos uma preponderância em privilegiar os processos de construção do conhecimento científico em detrimento dos que se detêm sobre o produto, o que entendemos como um aspecto favorável, pois busca proporcionar ao aluno contato com uma perspectiva que inclui o dinamismo da ciência, auxiliando o entendimento sobre o papel da ciência e suas relações com a sociedade. Há assim uma confirmação do que a literatura pertinente ao tema sugere como ideal. Esse fato nos leva a questionar até que ponto a teoria exerce influência sobre a prática pedagógica e/ou vice-versa.

Observamos, nas atividades propostas nos trabalhos, pouco estímulo dado à percepção dos alunos a respeito da relação direta entre o conhecimento sobre produção de ciências e as tecnologias usadas no cotidiano. Acreditamos que, em pesquisas futuras, essa questão mereça ser mais bem explicitada e aprofundada.

$\mathrm{O}$ estudo apresentado, como já mencionado, trouxe um recorte de uma pesquisa maior que busca estender os dados considerados nesse artigo, na inclusão de outros relevantes eventos da pesquisa em ensino de ciências. Além disso, o propósito de continuidade inclui a análise de aspectos epistêmicos dos trabalhos, assim como e dos limites identificados pelos autores dos trabalhos da implementação das propostas pedagógicas voltadas para a HFC.

\section{REFERÊNCIAS}

ASSOCIAÇÃO BRASILEIRA DE PESQUISA EM EDUCAÇÃO EM CIÊNCIAS.

ABRAPEC. Menu ENPEC. Anteriores. Disponível em: < http://abrapecnet.org.br/wordpress/pt/enpecs-anteriores>. Acesso em: 22 jul. 2017.

AULER, D.; DELIZOICOV, D. Alfabetização científico-tecnológica para quê? Ensaio: pesquisa em educação em ciências. vl. 3, n. 2, p. 122-134, 2001.

BACHELARD, G. A formação do espírito científico: contribuição para uma psicanálise do conhecimento. Trad: Estela dos Santos Abreu. 1. ed. Rio de Janeiro: Contraponto, 1996.

BASTOS FILHO, J. B. Qual história e qual filosofia da ciência são capazes de melhorar o ensino de física? In: PEDUZZI, L. O. Q.; MARTINS, A. F. P.; FERREIRA, J. M. H.

(Org.). Temas de história e filosofia da ciência no ensino. Natal: EDUFRN, 2012. p. 6583. 
CACHAPUZ, A. Do ensino de ciências: seis ideias que aprendi. In: CARVALHO, A. M. P.; CACHAPUZ, A.; GIL-PÉREZ, D. (Org.). O ensino das ciências como compromisso científico e social: os caminhos que percorremos. São Paulo: Cortez, 2011. cap. 1, p. 1132 .

CONSTANTINO, E. S.; DIAS, M. C.; LEÃO, M. B. A construção histórica da tabela periódica como proposta de aprendizagem In: ENCONTRO NACIONAL DE PESQUISA EM EDUCAÇÃO EM CIÊNCIAS, 3., 2001, Atibaia. Anais... Atibaia SP: ABRAPEC, 2001. Não paginado. Disponível em: <http://abrapecnet.org.br/atas_enpec/ienpec/ienpec.html>. Acesso em: 21 out. 2018.

COSTA, P. S.; CUNHA, A. A. AIRES, J. A. Análise de uma proposta didática sobre radioatividade a partir da história e filosofia da ciência. In: ENCONTRO NACIONAL DE PESQUISA EM EDUCAÇÃO EM CIÊNCIAS, 8., 2011, Campinas, Anais... Campinas, SP: ABRAPEC, 2011. p. 1-12.

CHASSOT, A. Alfabetização científica: uma possibilidade para a inclusão social. Revista Brasileira de Educação, ANPEd, n. 26, 2003. p. 89-100.

CUNHA, M. B. A percepção de ciência e tecnologia dos estudantes de ensino médio e a divulgação científica. 2009. Tese (Doutorado em Educação) - Universidade de São Paulo, São Paulo, 2009.

DELIZOICOV, D.; SLONGO, I.; LORENZETTI, L. ENPEC: 10 anos de disseminação da pesquisa em educação em ciências. ENCONTRO NACIONAL DE PESQUISA EM EDUCAÇÃO EM CIÊNCIAS, 6., 2007, Florianópolis, Atas... Florianópolis: ABRAPEC, 2007. p. 1-12.

FERREIRA, N. S. A. As pesquisas denominadas "estado da arte". Educação \& Sociedade, v. 23, n. 79, p. 257-272, 2002.

KRÜGER, A. G.; TEIXEIRA, M. L.; AIRES, J. A tabela periódica a partir da abordagem história e filosofia da ciência: análise de uma proposta didática. In: ENCONTRO NACIONAL DE PESQUISA EM EDUCAÇÃ̃ EM CIÊNCIAS, 8, 2011, Campinas, Anais... Campinas, SP: ABRAPEC, 2011. p. 1-11.

MARTINS, A. F. P. História e filosofia: há muitas pedras nesse caminho. Caderno Brasileiro de Ensino de Física, v. 24, n. 1, p. 112-131, 2007.

MARTINS, R. A. História e história da ciência: encontros e desencontros. In: CONGRESSO LUSO-BRASILEIRO DA CIÊNCIA E DA TÉCNICA, 1., 2001, Évora. Atas... Évora: Universidade de Évora; Universidade de Aveio, 2001. p. 11-46.

MARTINS, R. A. Introdução: a história das ciências e seus usos na educação. In: SILVA, C. C. (Org.). Estudos de história e filosofia das ciências: subsídios para aplicação no ensino. São Paulo: Livraria da Física, 2006. p. 27-30. 
Artigo

doi: $10.20396 /$ rho.v18i4.8652249

MATTHEWS, M. R. História, filosofia e ensino de ciências: a tendência atual de reaproximação. Caderno Catarinense de Ensino de Física, Florianópolis, v. 12, n. 3, 1995, p. 164-214.

MATTIAZZO-CARDIA, E.; UENO, R.; MORAES, M. S. A dívida pública como tema transversal/político social em aulas de matemática no ensino fundamental. In:

ENCONTRO NACIONAL DE PESQUISA EM EDUCAÇÃO EM CIÊNCIAS, 5., 2005, Bauru, Anais... Bauru, SP: ABRAPEC, 2005, p. 1-12.

MOREIRA, I. C. A inclusão social e a popularização da ciência e tecnologia no Brasil. Inclusão Social. Brasília, v. 1, n. 2, p. 11-16, 2006.

NOGUEIRA, L. V.; FREITAS, K. C. Análise de aspectos da natureza da ciência (NdC) e motivacionais em estudantes do ensino médio mediada por sequência didática centrada na replicação de experimentos históricos darwinianos. In: ENCONTRO NACIONAL DE PESQUISA EM EDUCAÇÃO EM CIÊNCIAS, 10., 2015, Águas de Lindóia Anais... Águas de Lindóia, SP ABRAPEC: 2015, p. 1-8.

OLIVEIRA, R. A.; SILVA, A. P. B. História da ciência e ensino de física: uma análise meta-historiográfica. In: PEDUZZI, L. O. Q.; MARTINS, A. F. P.; FERREIRA, J. M. H. (Org.). Temas de história e filosofia da ciência no ensino. Natal: EDUFRN, 2012. cap. 2, p. 41-64.

RODRIGUES, H. O.; SILVA, R. S. Papiro de Moscou e RHIND: resolução de equação do $2^{\circ}$ Grau. In: ENCONTRO NACIONAL DE PESQUISA EM EDUCAÇÃ O EM CIÊNCIAS, 5., 2005, Bauru, Anais... Bauru, SP: ABRAPEC, 2005, p. 1-1.

RODRIGUES, R. de. C. B.; FURTADO, W. W. Jogos teatrais de história da ciência. In: ENCONTRO NACIONAL DE PESQUISA EM EDUCAÇÃO EM CIÊNCIAS, 8., 2011, Campinas, Anais... Campinas, SP: ABRAPEC, 2011, p. 1-12.

RODRIGUES, R. de. C. B.; FURTADO, W. W. Jogos teatrais no estudo da construção histórica do conhecimento sobre modelos atômicos no ensino fundamental. In: ENCONTRO NACIONAL DE PESQUISA EM EDUCAÇÃO EM CIÊNCIAS, 9., 2013, Águas de Lindóia, Anais... Águas de Lindóia, SP: ABRAPEC, 2013. p. 1-8.

ROSSETO, G. A. R. S. et al. Desafios dos estudos "estado da Arte": Estratégias de pesquisa na pós-graduação. Educação: Saberes e Práticas, v. 2, n. 1, p. 1-15, 2013.

SANTOS, E. G.; SCHEID, N. M. J. História da ciência na educação básica: contribuições do cinema. In: ENCONTRO NACIONAL DE PESQUISA EM EDUCAÇÃO EM CIÊNCIAS, 8., 2011, Campinas, Anais... Campinas, SP: ABRAPEC, 2011. p. 1-13.

SANTOS NETO, E. R.; OLIVEIRA, M. de. P. Identificando o obstáculo cultural em aulas de física do ensino médio. In: ENCONTRO NACIONAL DE PESQUISA EM EDUCAÇÃO EM CIÊNCIAS, 5., 2005, Bauru, Anais... Bauru, SP: ABRAPEC. 2005. p. $1-12$. 
SARMENTO, A. C. et al. Como ensinar citologia para estudantes do ensino médio e promover uma visão informada sobre características da ciência. In: ENCONTRO NACIONAL DE PESQUISA EM EDUCAÇÃO EM CIÊNCIAS, 10., 2015, Águas de Lindóia, Anais... Águas de Lindóia, SP: ABRAPEC, 2015. p. 1-8.

SILVA, T. T.; PRESTES, E. B. História da biologia no ensino: análise das concepções de alunos sobre os métodos científicos, através de episódios históricos de Charles Darwin. In: ENCONTRO NACIONAL DE PESQUISA EM EDUCAÇÃO EM CIÊNCIAS, 8., 2011, Campinas, Anais... Campinas, SP: ABRAPEC, 2011. p. 1-13.

TEIXEIRA. S. T.; GRECA, I. M.; FREIRE JUNIOR, O. Uma revisão sistemática das pesquisas publicadas no Brasil sobre o uso didático de história e filosofia da ciência no ensino de física. In: PEDUZZI, L. O. Q., FERRER, A. P. M., FERREIRA, J. M. H. F. (Org.). Temas de história e filosofia da ciência no ensino. Natal: EDUFRN, 2012. cap.1, p. $9-40$.

TODESCO, S. A., RODRIGUES, T. S.; AIRES, J. A., História e filosofia da ciência: uma proposta para o ensino de ácidos e bases. In: ENCONTRO NACIONAL DE PESQUISA EM EDUCAÇÃO EM CIÊNCIAS, 8, 2011, Campinas, Anais... Campinas, SP: ABRAPEC, 2011, p. 1-12.

VANNUCCHI, A. I. História e filosofia da ciência: da teoria para a sala de aula. 1997. 131 f. Dissertação (Mestrado em Ensino de Física) - Universidade de São Paulo, São Paulo, 1997.

VITAL, A.; GUERRA, A. A utilização de textos na implementação da história e a filosofia da ciência no ensino de física In: ENCONTRO NACIONAL DE PESQUISA EM EDUCAÇÃO EM CIÊNCIAS, 10., 2015, Águas de Lindóia, Anais... Águas de Lindóia, SP: ABRAPEC, 2015. p. 1-8.

Notas

\footnotetext{
${ }^{1}$ Mestre em Ensino de Ciências pelo Instituto de Educação, Ciência e Tecnologia do Rio de Janeiro (IFRJ/Nilópolis), Especialista em Educação e Divulgação Científica (IRFJ/ Mesquita), docente de História da Prefeitura de Araruama.

${ }^{2}$ Doutora em História das Ciências e da Saúde (COC/FIOCRUZ); docente do Programa de Pós-Graduação em Ensino de Ciências- Instituto Federal de Educação, Ciência e Tecnologia do Rio de Janeiro (IFRJ/Nilópolis), da Especialização em Educação e Divulgação Científica (IFRJ/Mesquita).

${ }^{3}$ Doutora em Educação em Ciências e Saúde pela Universidade Federal do Rio de Janeiro(UFRJ); docente do Programa de Pós-Graduação em Ensino de Ciências (acadêmico e profissional) - Instituto Federal de Educação, Ciência e Tecnologia do Rio de Janeiro (IFRJ/Nilópolis).

${ }^{4} \mathrm{O}$ estudo apresentado é um recorte de uma dissertação de mestrado que buscou analisar quatro grandes eventos da área de ensino de ciências, as propostas pedagógicas, com intervenção em sala de aula, com ênfase na perspectiva da HFC.

${ }^{5}$ Antiga área de ensino de ciências e matemática, criada em 2000.
} 


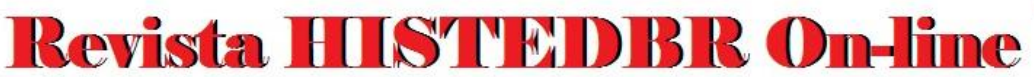

Submetido em: 16/04/2018

Aprovado em: 21/09/2018

Publicado em: 18/12/2018 